\title{
microRNA expression profiling in fetal single ventricle malformation identified by deep sequencing
}

\author{
ZHANG-BIN YU ${ }^{1}$, SHU-PING HAN ${ }^{1}$, YUN-FEI BAI ${ }^{2}$, CHUN ZHU $^{1}$, YA PAN $^{1}$ and XI-RONG GUO ${ }^{1}$ \\ ${ }^{1}$ Department of Pediatrics, Nanjing Maternal and Child Health Hospital Affiliated of Nanjing Medical University, \\ Nanjing 210004; ${ }^{2}$ State Key Laboratory of Bioelectronics, School of Biological Science \\ and Medical Engineering, Southeast University, Nanjing 210096, P.R. China
}

Received July 13, 2011; Accepted September 2, 2011

DOI: $10.3892 / \mathrm{ijmm} .2011 .797$

\begin{abstract}
RNAs (miRNAs) have emerged as key regulators in many biological processes, particularly cardiac growth and development, although the specific miRNA expression profile associated with this process remains to be elucidated. This study aimed to characterize the cellular microRNA profile involved in the development of congenital heart malformation, through the investigation of single ventricle (SV) defects. Comprehensive miRNA profiling in human fetal SV cardiac tissue was performed by deep sequencing. Differential expression of 48 miRNAs was revealed by sequencing by oligonucleotide ligation and detection (SOLiD) analysis. Of these, 38 were down-regulated and 10 were up-regulated in differentiated SV cardiac tissue, compared to control cardiac tissue. This was confirmed by real-time quantitative reverse transcriptionpolymerase chain reaction (qRT-PCR) analysis. Predicted target genes of the 48 differentially expressed miRNAs were analyzed by gene ontology and categorized according to cellular process, regulation of biological process and metabolic process. Pathway-Express analysis identified the WNT and mTOR signaling pathways as the most significant processes putatively affected by the differential expression of these miRNAs. The candidate genes involved in cardiac development were identified as potential targets for these differentially expressed microRNAs and the collaborative network of microRNAs and cardiac development related-mRNAs was constructed. These data provide the basis for future investigation of the mechanism of the occurrence and development of fetal SV malformations.
\end{abstract}

\section{Introduction}

Congenital heart disease (CHD) is the most common birth defect, occurring in 4 to 8 per 1,000 live births (1). In infants who die before term, however, there is a much higher inci-

Correspondence to: Dr Xi-Rong Guo or Dr Shu-Ping Han, Department of Pediatrics, Nanjing Maternal and Child Health Hospital Affiliated of Nanjing Medical University, Nanjing 210004, P.R. China E-mail: xrguo@njmu.edu.cn

E-mail: shupinghan@njmu.edu.cn

Key words: microRNA, single ventricle, deep sequencing dence of CHD. Among these CHD lesions, single ventricle (SV) malformation, which occurs in $\sim 1$ of every 20,000 live births (2), is a complex cardiac malformation that represents a significant therapeutic challenge. It is characterized by a single ventricle, with symptoms after birth depending on the severity and type of the defect. Symptoms include cyanosis, respiratory problems, difficulty feeding and lethargy. Without treatment patients with SV have a short life due to congestive heart failure or arrhythmias. Fifty percent of affected individuals die within 1 month of birth and 74\% in the first 6 months (3).

Collective evidence indicates a role for genetic factors in the SV malformation. Three targeted single-gene disruptions in the mouse have been reported to result in SV prenatally: the Mef2c null, the dHAND/Hand2 null and the fog-2 null. All three display right ventricular hyperplasia and the fog-2 null mouse also displays a common atrioventricular orifice situated almost entirely over the future left ventricle (4). Elucidating the genetic and molecular mechanisms underlying SV development will facilitate the development of strategies to prevent this congenital malformation. microRNAs (miRNAs) have emerged as key regulators in many biological processes, from cardiac development to disease, at almost all organismal levels through mRNA degradation or translational repression of their targets (5). Recently, their role has been highlighted in regulating cardiac function, particularly growth and development (6). Targeted deletion of miR-1-2 in mice resulted in 50\% lethality mainly due to major ventricular wall defects (7). The absence of miR-133a expression was associated with ectopic expression of smooth muscle genes in the heart and aberrant cardiomyocyte proliferation (8). Disruption of miR-138 function led to ventricular expansion of gene expression normally restricted to the atrioventricular valve region and, ultimately, to disrupted ventricular cardiomyocyte morphology and cardiac function (9). These miRNAs potentially regulate several genes encoding proteins involved in apoptosis, cell proliferation, signal transduction, transcriptional regulation and development (10). In contrast, global changes in the expression of miRNAs during cardiac development have not been extensively investigated. This study aimed to characterize the cellular miRNAs involved in the development of congenital heart malformations, through investigation of the patterns of the SV malformation. Comprehensive miRNA profiling in human fetal cardiac tissue of SV was performed through deep sequencing. 
Table I. RT primer sequences.

Gene name

hsa-miR-214

hsa-miR-19b

hsa-miR-126

hsa-miR-200a

hsa-miR-10a

hsa-miR-206
RT primer

5'-GCTAAATTCATAACCGGCCGGCCAACTGCCTGT-3'
5'-CCCTACCGCGCAATAAACTTCAGTTTTGC-3'
5'-GCTCGACCTCGGAAACTATGGCATTATTAC-3'
5'-ACGCCACAATTAAGCCACATCGTTAC-3'
5'-GCTTGTCGGTTAAACACTGTCACAAATTCG-3'
5'-ACGAGTTTAGAGCCGGATAGCCACACAC-3'

Table II. Primers for real-time RT-PCR.

\begin{tabular}{lll}
\hline Gene name & \multicolumn{1}{c}{ Forward primer } & \multicolumn{1}{c}{ Reverse primer } \\
\hline hsa-miR-214 & 5'-CGCTAAATTCATAACCGGCCAA-3' & 5'-ACTCACACAGCAGGCACA-3' \\
hsa-miR-19b & 5'-AATCCCTACCGCGCAATAAACT-3' & 5'-CCGCTGTGCAAATCCATGC-3' \\
hsa-miR-126 & 5'-CTGCTCGACCTCGGAAACTATG-3' & 5'-AGCATGAATCGTACCGTGAGT-3' \\
hsa-miR-200a & 5'-CCTACGCCACAATTAACAAGCC-3' & 5'-GCCGTCTAACACTGTCTGGTA-3' \\
hsa-miR-10a & 5'-AGGCTTGTCGGTTAAACACTGT-3' & 5'-CCGGTACTACCCTGTAGATCCG-3' \\
hsa-miR-206 & 5'-TGACGAGTTTAGAGCCGGATAG-3' & 5'-GCGTTGTCTGGAATGTAAGGAAGT-3' \\
U6 & 5'-CTCGCTTCGGCAGCACA-3' & 5'-AACGCTTCACGAATTTGCGT-3' \\
\hline
\end{tabular}

\section{Materials and methods}

Patients and tissue samples. Cardiac tissue was obtained from spontaneously aborted fetuses at the Perinatal Medical Center of Nanjing Maternal and Child Health Hospital of Nanjing Medical University. Written informed consent was obtained prior to surgery. Ethical approval for the consent forms and the protocols for evaluation of tissues were obtained from the resident Ethics Committee. Aborted fetuses with SV (n=3) were compared with a control group of aborted fetuses without cardiac malformations $(n=3)$. All fetuses were at 20-22 weeks of gestation. Immediately after abortion and post-mortem, cardiac tissue was removed from the ventricles, snap-frozen in liquid nitrogen and stored at $-80^{\circ} \mathrm{C}$ for later analysis. Total miRNA was extracted from human fetal cardiac tissue using the mirVana miRNA Isolation kit (Applied Biosystems, USA) according to the instructions provided by the manufacturer.

SOLiD sequencing and sequence analysis. Samples of miRNA $(100 \mathrm{ng})$ isolated from fetal cardiac tissue were processed into sequencing libraries using the Small RNA Expression kit (Applied Biosystems). Briefly, RNA was ligated overnight with the adapters from the kit; reverse transcribed, RNase H-treated and PCR amplified before agarose gel electrophoresis for size selection of miRNAs containing inserted sequences of 16-61 nucleotides (nt). Libraries were amplified onto beads using emulsion PCR, deposited on slides and sequenced using the Sequencing by Oligonucleotide Ligation and Detection (SOLiD) v2 sequencing system (Applied Biosystems) at the State Key Lab of Bioelectronics Laboratory, Southeast University, China. Data were analyzed with the SOLiD System Small RNA Analysis Pipeline Tool (RNA2MAP) using the following parameters for alignments: maximum length (18 nt) and tolerance of 3 mismatches when generating initial seeds locations; in the extension step, less than 6 mismatches were allowed in full length mapping. Acceptable sequences were compared with human miRBase database (release 14.0, http:// www.mirbase.org/) sequences (Sanger). The threshold for selection was set conservatively to include beads sampled a minimum of 10 times in any of the libraries.

Validation of differentially expressed miRNAs. Real-time qRT-PCR was performed to confirm the differential expression of miRNAs idenitified by SOLiD sequencing. Briefly, total-RNA was isolated from fetal cardiac tissue using TRIzol (Invitrogen, Carlsbad, CA). Single-strand cDNA was synthesized as follows: the reverse transcription mixture contained $2 \mu \mathrm{l}$ total-RNA, $1 \mu \mathrm{l}$ hsa-miRNA reverse primer (Table I), $1 \mu \mathrm{l}$ ReverTra Ace, $4 \mu \mathrm{l} 5 \mathrm{X}$ buffer, $2 \mu \mathrm{l}$ dNTP mix (10 mM), $1 \mu \mathrm{l}$ RNasin, $1 \mu \mathrm{l}$ random primer and $8 \mu \mathrm{l}$ RNase-free $\mathrm{H}_{2} \mathrm{O}(20 \mu \mathrm{l}$ total volume). The reaction was performed at $30^{\circ} \mathrm{C}$ for $10 \mathrm{~min}$ and $42^{\circ} \mathrm{C}$ for $20 \mathrm{~min}$, followed by heat inactivation at $99^{\circ} \mathrm{C}$ for $5 \mathrm{~min}$ and a final incubation at $4^{\circ} \mathrm{C}$ for $5 \mathrm{~min}$. For real-time PCR, $2 \mu \mathrm{l}$ cDNA was added to $28 \mu \mathrm{l}$ master mix containing $0.5 \mu \mathrm{l} \mathrm{SYBR-Green} \mathrm{(Applied} \mathrm{Biosystems)} \mathrm{and} 0.5 \mu \mathrm{l}$ forward and reverse primers. cDNA was amplified over 35 cycles using the Applied Biosystems 7300 real-time PCR system. Primer sequences are shown in Table II. Data were analyzed by the iCycler $^{\text {TM }}$ iQ Optical System Software, Version 3.0a (Bio-Rad Laboratories). The relative level of hsa-miRNA was calculated relative to U6 RNA (internal control) using the $2^{-\Delta \Delta C t}$ method.

Target prediction, gene ontology and Pathway-Express analysis. A total of 48 predicted targets of miRNAs differentially expressed in SV were identified using MicroCosm (www.ebi. ac.uk/enright-srv/microcosm), TargetScan (www.targetscan. 


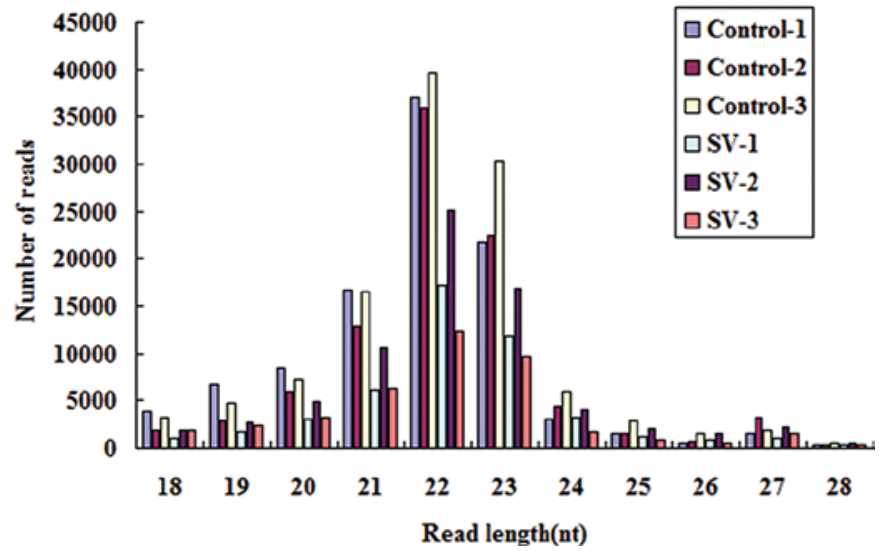

Figure 1. Length distribution of sequenced miRNAs.

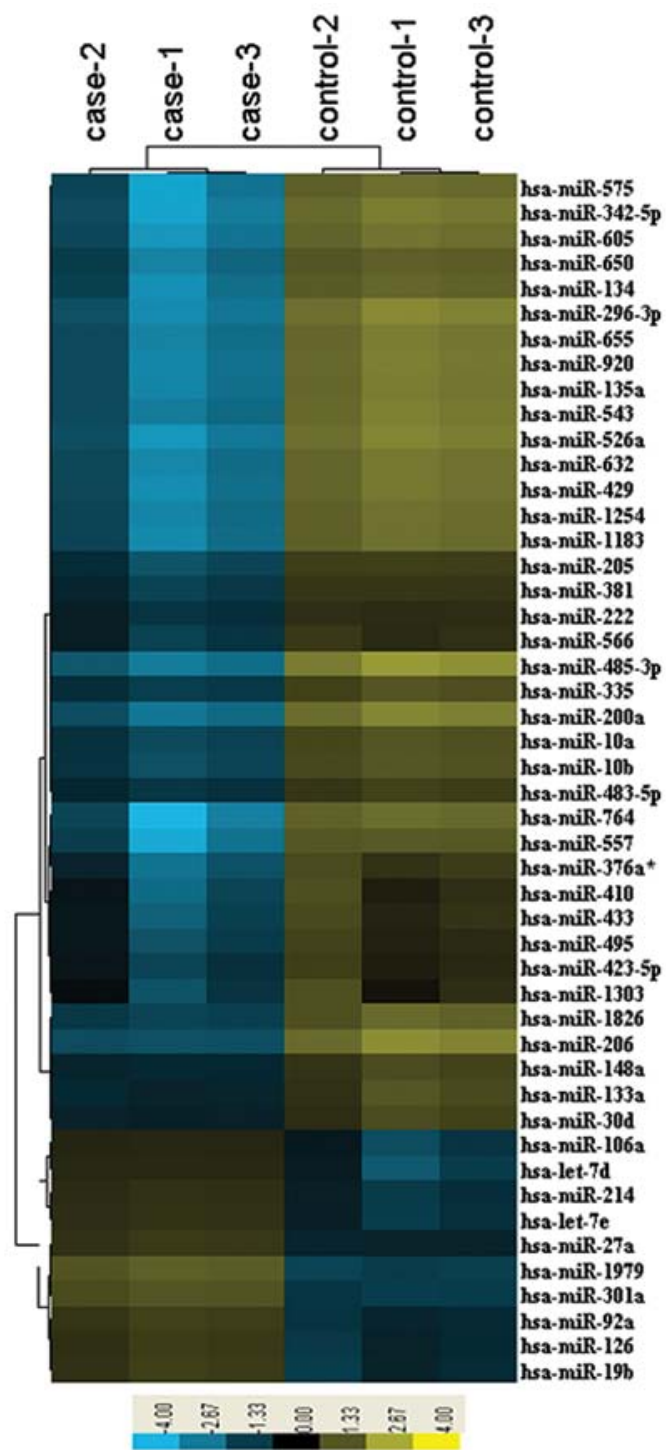

Figure 2. Hierarchical cluster analysis of differentially expressed miRNAs in $\mathrm{SV}$ and control cardiac tissues.

org) and the microRNA.org (www.microrna.org). These were included in gene ontology (GO) analysis (http://www.babelomics.bioinfo.cipf.es/). Functional category enrichment based on

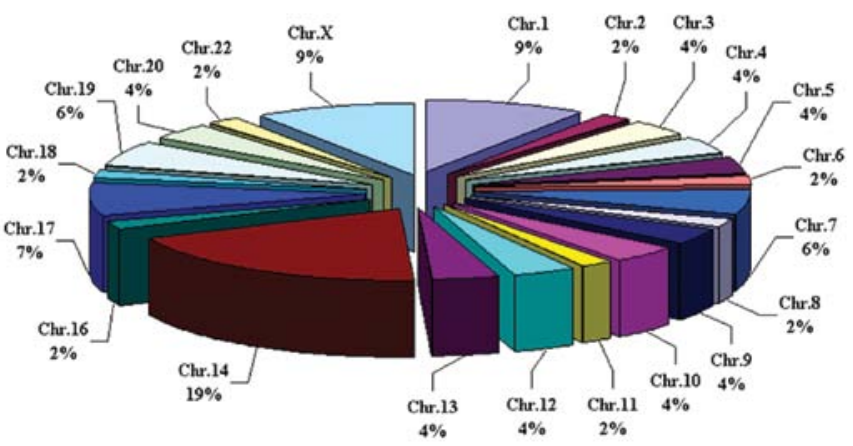

Figure 3. Genomic loci of the sequenced miRNAs. Chr, chromosome.

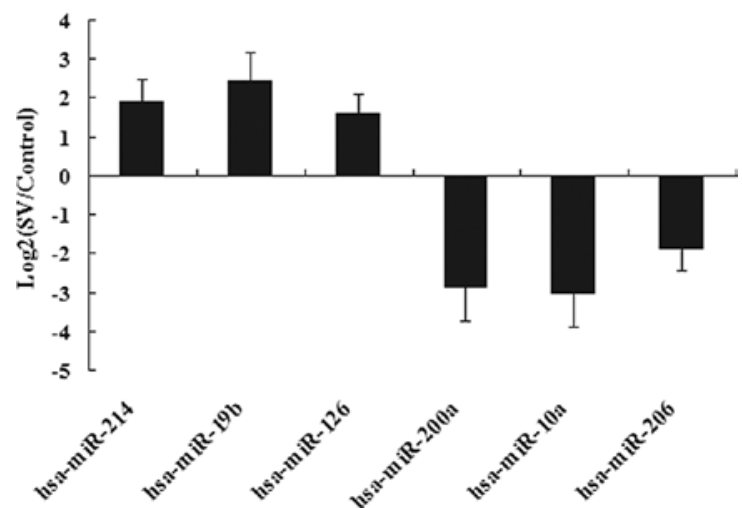

Figure 4. Quantitation of miRNA expression levels in the SV and control cardiac tissues by real-time qRT-PCR. Y values are the ratio of two groups of miRNAs calculated using the equation $\log 2$ (SV/Control).

the GO terms was evaluated for the targets of these differentially expressed miRNAs. Pathway-Express (http://vortex.cs.wayne. edu/) categorized the predicted targets according to KEGG pathways. A graphical representation of the network (mRNAmiRNA) of the miRNAs and their predicted targets involved in cardiac development identified by IPA analysis (http://www. ingenuity.com/) is shown in Fig. 9.

Statistical analysis. Putative miRNA candidates were selected according to the following criteria: i) at least 10 copies by SOLiD sequencing; ii) fold-change calculated based on the normalized counts between SV cardiac tissue and control cardiac tissue, $>2$; iii) statistical significance of differences in expression levels between SV cardiac tissue and control cardiac tissue at P-values $<0.05$. Real-time qRT-PCR data are presented as the mean \pm SEM.

\section{Results}

Overview of the SOLiD sequencing data. After SOLiD sequencing, raw reads were obtained from the small RNA library. Low-quality reads were removed, and the 39 adaptor sequence was trimmed. The 59 adaptor contaminants were also removed. Small RNA sequences ranging in size from 18-28 nt were retrieved from the raw data set. The size distribution of the reads is shown in Fig. 1. The majority of the small RNAs were between 21 and $23 \mathrm{nt}$ in size. Sequences of $22 \mathrm{nt}$ accounted for 30.4 to $39.1 \%$ of total sequence reads in the six samples, which 


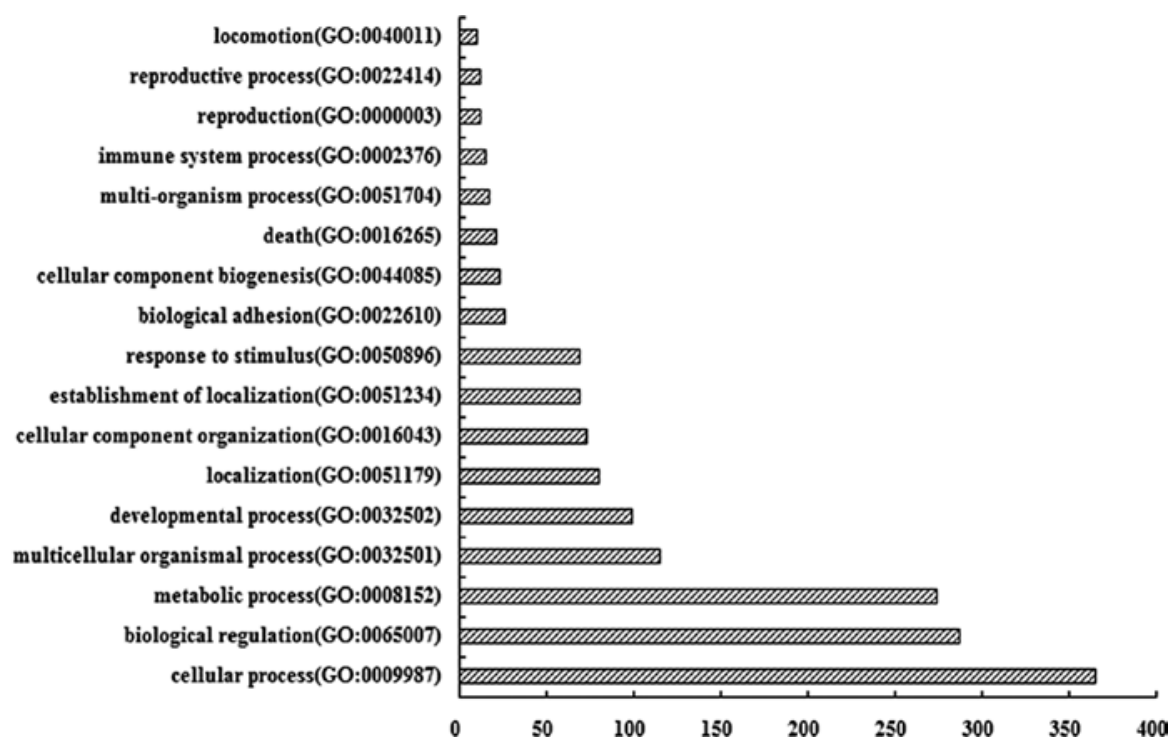

Figure 5. Predicted target gene ontology terms in the biological process category.

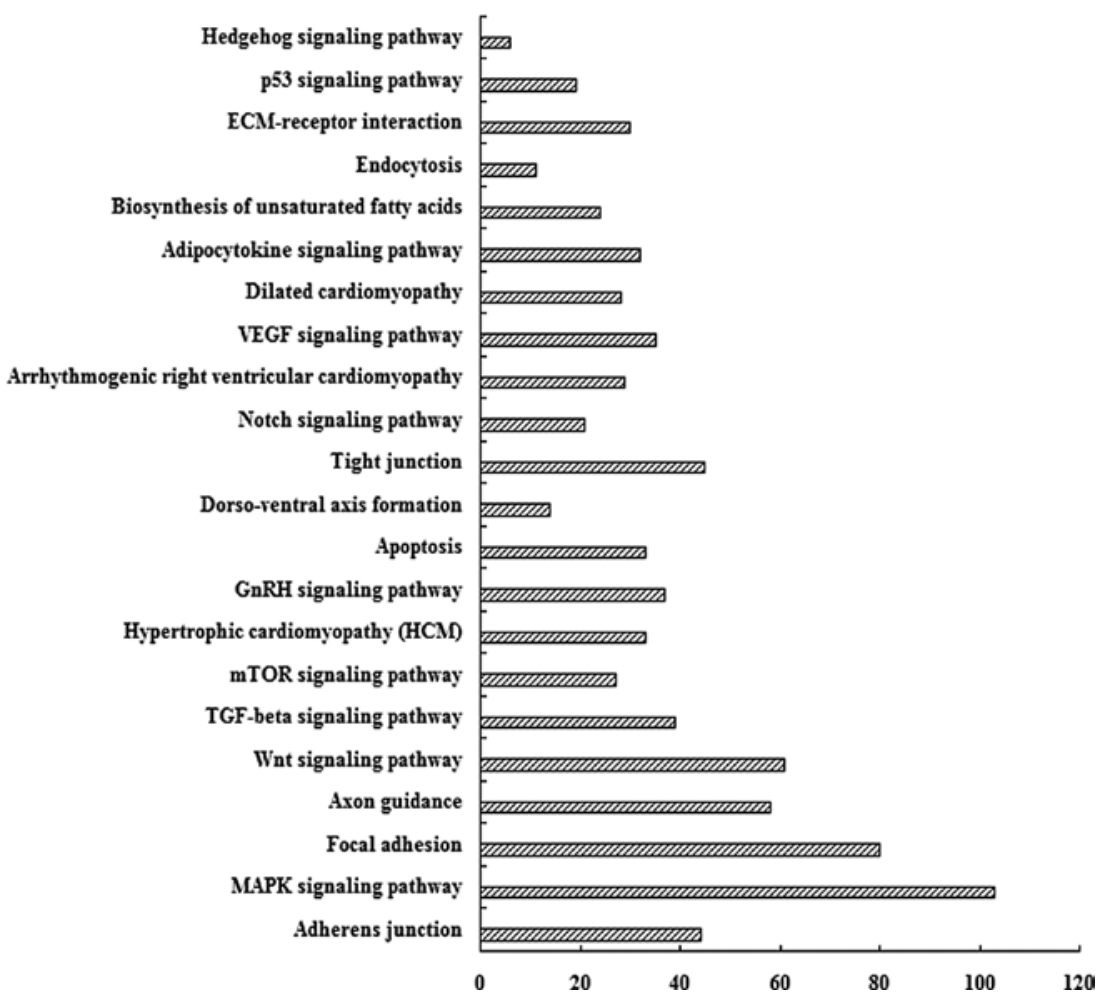

Figure 6. Predicted target genes identified by Pathway-Express analysis.

is the typical size range for Dicer-derived products. The $23 \mathrm{nt}$ size class was also dominant.

Aberrant miRNAs in SV cardiac tissues identified by SOLiD sequencing. A total of 48 miRNAs identified by differential expression profiling of $\mathrm{SV}$ and control cardiac tissue were retained for further hierarchical cluster analysis (Fig. 2). Normalization of the raw data revealed up-regulation of 10 miRNAs and downregulation of 38 miRNAs in SV cardiac tissues compared with normal cardiac tissues (Table III). The 48 differentially expressed miRNAs were located in the human chromosomes 14, 1 and X
(19, 9 and $9 \%$, respectively). The distribution of genomic loci in these chromosomes are shown in Fig. 3.

Validation of differentially expressed miRNAs. SOLiD sequencing results were validated by real-time qRT-PCR expression analysis of SV and control cardiac tissues. Up-regulated miRNAs (hsa-miR-214, hsa-miR-19b and hsa-miR-126) and down-regulated miRNAs (hsa-miR-200a, hsa-miR-10a and hsa-miR-206) were selected at random for analysis. The expression data obtained by real-time qRT-PCR analysis were comparable with the microarray data (Fig. 4). 


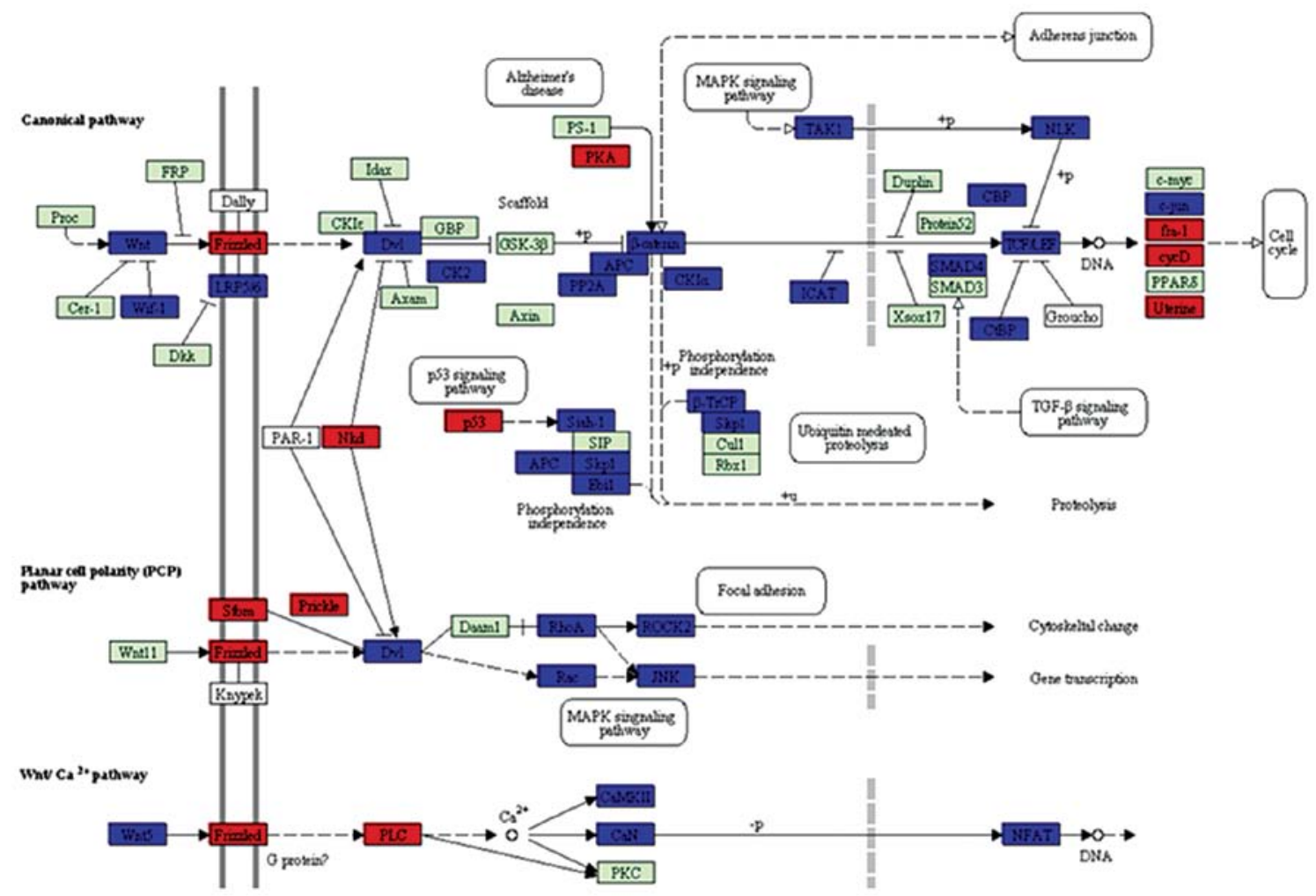

Figure 7. The WNT pathway identified by Pathway-Express analysis. The predicted up-regulated (red) and down-regulated (blue) target genes.

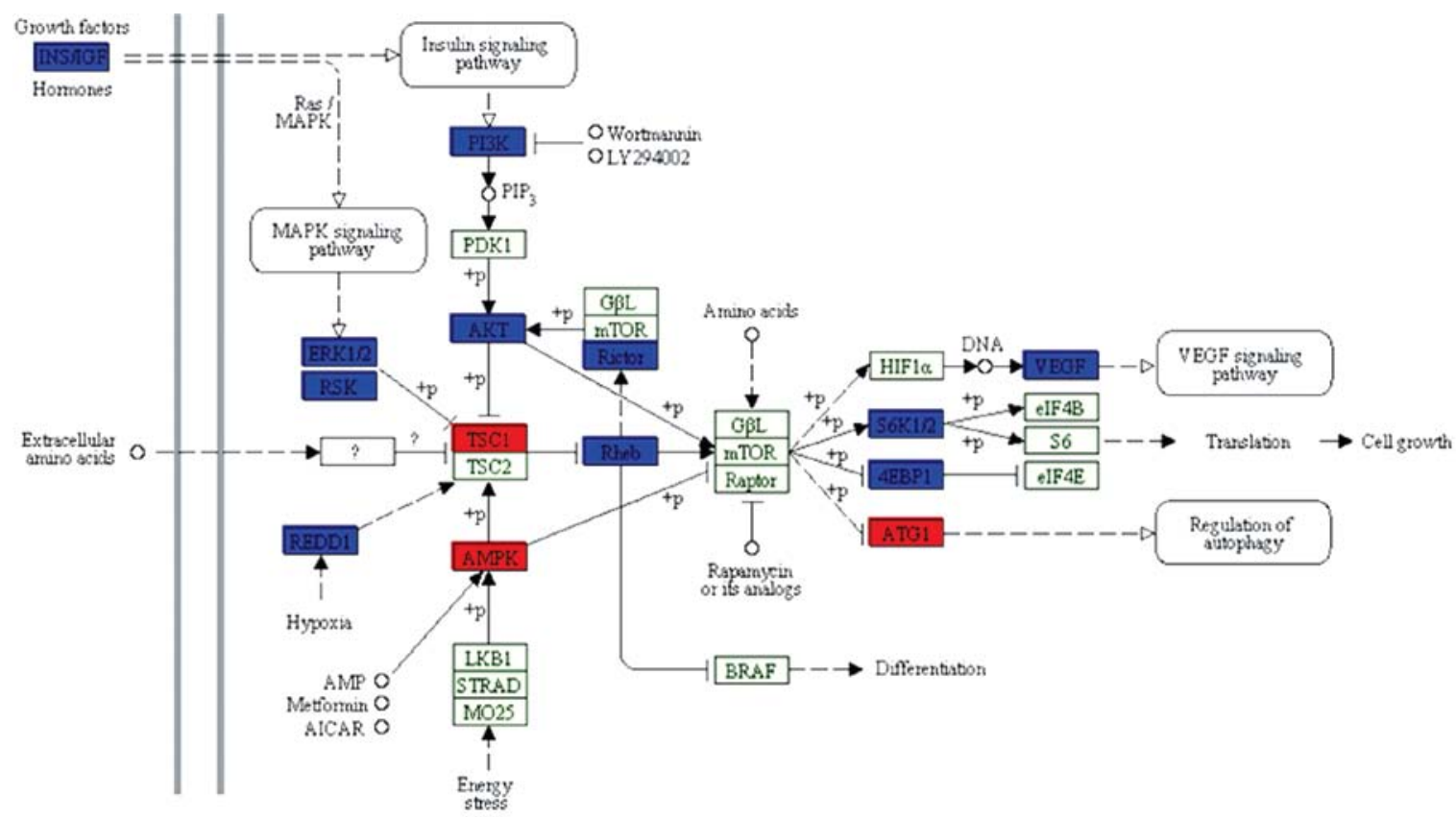

Figure 8. The mTOR pathway identified by Pathway-Express analysis. The predicted up-regulated (red) and down-regulated (blue) target genes.

Target prediction, gene ontology and Pathway-Express analysis. Predicted targets of the 48 differentially expressed miRNAs were determined using MicroCosm, TargetScan and microRNA.org. These target genes were grouped into different categories. The top $17 \mathrm{GO}$ terms are shown in Fig. 5. The majority of the targets were categorized according to cellular process, regulation of biological process, and metabolic process, thus indicating intense biological change in fetuses with SV. Pathway-Express analysis identified 22 pathways significant at the $1 \%$ level (Fig. 6), most of which were consistent with current knowledge of cardiac development. The most significant processes putatively affected by the differential expression of miRNAs were the WNT and mTOR signaling pathways (Figs. 7 and 8, respectively). 
Table III. The miRNAs differentially expressed between single ventricle (SV) and control cardiac tissues.

\begin{tabular}{|c|c|c|c|c|}
\hline Name & $\begin{array}{l}\text { Chromosomal } \\
\text { localization }\end{array}$ & $\begin{array}{c}\text { Ratio (case/control) } \\
\text { (normalization) }\end{array}$ & $\begin{array}{c}\log 2 \\
(\mathrm{SV} / \mathrm{Control})\end{array}$ & P-value \\
\hline hsa-miR-485-3p & $14 q 32.31$ & 0.04 & -4.53 & $6.26 \mathrm{E}-04$ \\
\hline hsa-miR-296-3p & $20 q 13.32$ & 0.05 & -4.35 & $3.06 \mathrm{E}-04$ \\
\hline hsa-miR-526a & $19 q 13.42$ & 0.05 & -4.35 & 2.13E-04 \\
\hline hsa-miR-342-5p & $14 q 32.2$ & 0.05 & -4.26 & $1.31 \mathrm{E}-04$ \\
\hline hsa-miR-764 & $\mathrm{Xq} 23$ & 0.06 & -4.09 & $3.48 \mathrm{E}-05$ \\
\hline hsa-miR-920 & $12 \mathrm{p} 12.1$ & 0.06 & -4.08 & $2.15 \mathrm{E}-04$ \\
\hline hsa-miR-200a & 1p36.33 & 0.06 & -4.07 & $3.66 \mathrm{E}-04$ \\
\hline hsa-miR-135a & $3 \mathrm{p} 21.1,12 \mathrm{q} 23.1$ & 0.06 & -4.02 & $1.83 \mathrm{E}-04$ \\
\hline hsa-miR-655 & $14 q 32.31$ & 0.06 & -3.99 & $2.10 \mathrm{E}-04$ \\
\hline hsa-miR-543 & $14 q 32.31$ & 0.06 & -3.99 & 2.62E-04 \\
\hline hsa-miR-605 & $10 q 21.1$ & 0.06 & -3.98 & 9.09E-05 \\
\hline hsa-miR-429 & $1 \mathrm{p} 36.33$ & 0.06 & -3.97 & $1.28 \mathrm{E}-04$ \\
\hline hsa-miR-575 & $4 q 21.22$ & 0.07 & -3.93 & 4.94E-05 \\
\hline hsa-miR-632 & $17 q 11.2$ & 0.07 & -3.92 & $1.42 \mathrm{E}-04$ \\
\hline hsa-miR-1183 & $7 \mathrm{p} 15.3$ & 0.07 & -3.79 & $8.52 \mathrm{E}-05$ \\
\hline hsa-miR-1254 & $10 \mathrm{q} 21.3$ & 0.07 & -3.76 & $1.03 \mathrm{E}-04$ \\
\hline hsa-miR-206 & $6 \mathrm{p} 12.2$ & 0.08 & -3.70 & $1.10 \mathrm{E}-03$ \\
\hline hsa-miR-134 & $14 q 32.31$ & 0.08 & -3.67 & $3.53 \mathrm{E}-05$ \\
\hline hsa-miR-557 & $1 \mathrm{q} 24.2$ & 0.08 & -3.58 & $1.75 \mathrm{E}-05$ \\
\hline hsa-miR-650 & $22 q 11.22$ & 0.09 & -3.42 & 3.27E-05 \\
\hline hsa-miR-1826 & $16 \mathrm{p} 11.2$ & 0.14 & -2.86 & $5.12 \mathrm{E}-04$ \\
\hline hsa-miR-10b & $2 q 31.1$ & 0.16 & -2.67 & 7.69E-05 \\
\hline hsa-miR-10a & $17 q 21.32$ & 0.17 & -2.58 & $8.66 \mathrm{E}-05$ \\
\hline hsa-miR-376a & $14 \mathrm{q} 32.31$ & 0.18 & -2.48 & $1.15 \mathrm{E}-03$ \\
\hline hsa-miR-335 & 7q32.2 & 0.19 & -2.41 & $2.16 \mathrm{E}-04$ \\
\hline hsa-miR-205 & 1q32.2 & 0.19 & -2.38 & $2.12 \mathrm{E}-05$ \\
\hline hsa-miR-433 & $14 q 32.2$ & 0.24 & -2.03 & 7.07E-03 \\
\hline hsa-miR-410 & $14 q 32.31$ & 0.25 & -2.01 & $1.80 \mathrm{E}-02$ \\
\hline hsa-miR-381 & $14 q 32.31$ & 0.25 & -1.99 & $2.55 \mathrm{E}-05$ \\
\hline hsa-miR-483-5p & $11 \mathrm{p} 15.5$ & 0.25 & -1.99 & $5.46 \mathrm{E}-05$ \\
\hline hsa-miR-133a & $18 \mathrm{q} 11.2,20 \mathrm{q} 13.33$ & 0.27 & -1.91 & 2.99E-03 \\
\hline hsa-miR-148a & $7 \mathrm{p} 15.2$ & 0.27 & -1.88 & $6.11 \mathrm{E}-04$ \\
\hline hsa-miR-495 & $14 q 32.31$ & 0.28 & -1.82 & 7.27E-03 \\
\hline hsa-miR-566 & $3 p 21.31$ & 0.29 & -1.81 & $5.27 \mathrm{E}-04$ \\
\hline hsa-miR-30d & $8 q 24.22$ & 0.31 & -1.69 & $1.95 \mathrm{E}-03$ \\
\hline hsa-miR-1303 & $5 q 33.2$ & 0.31 & -1.68 & 3.79E-02 \\
\hline hsa-miR-222 & Xp11.3 & 0.32 & -1.63 & $4.96 \mathrm{E}-05$ \\
\hline hsa-miR-423-5p & $17 q 11.2$ & 0.33 & -1.60 & $8.75 \mathrm{E}-03$ \\
\hline hsa-miR-106a & $\mathrm{Xq} 26.2$ & 3.06 & 1.61 & $7.86 \mathrm{E}-04$ \\
\hline hsa-miR-27a & $19 \mathrm{p} 13.13$ & 3.08 & 1.62 & $2.50 \mathrm{E}-05$ \\
\hline hsa-miR-214 & $1 \mathrm{q} 24.3$ & 3.25 & 1.70 & 8.27E-05 \\
\hline hsa-let-7e & $19 q 13.41$ & 3.36 & 1.75 & $7.15 \mathrm{E}-05$ \\
\hline hsa-let-7d & $9 q 22.32$ & 3.48 & 1.80 & 7.62E-04 \\
\hline hsa-miR-126 & $9 q 34.3$ & 3.49 & 1.80 & $1.53 \mathrm{E}-04$ \\
\hline hsa-miR-92a & 13q31.3, Xq26.2 & 3.68 & 1.88 & $6.40 \mathrm{E}-05$ \\
\hline hsa-miR-19b & 13q31.3, Xq26.2 & 3.72 & 1.90 & $1.58 \mathrm{E}-04$ \\
\hline hsa-miR-301a & $17 q 22$ & 5.80 & 2.54 & $1.88 \mathrm{E}-05$ \\
\hline hsa-miR-1979 & $4 q 32.3$ & 6.93 & 2.79 & $2.91 \mathrm{E}-05$ \\
\hline
\end{tabular}




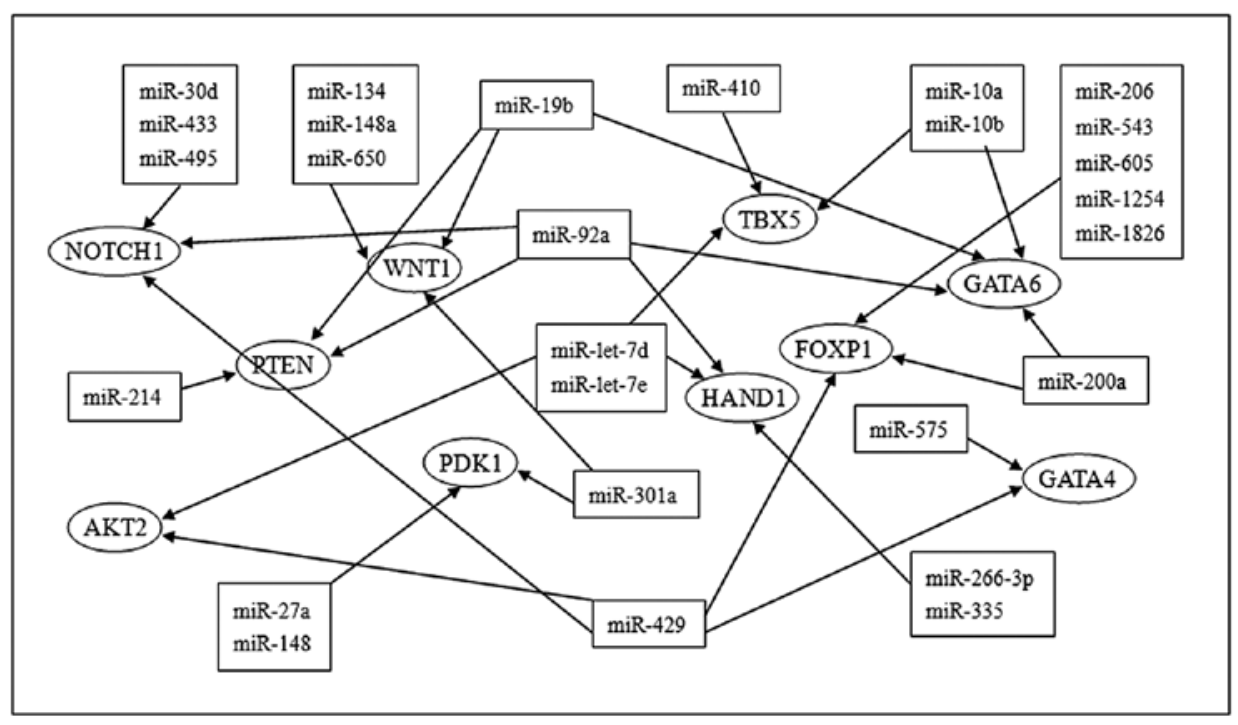

Figure 9. Network of target genes involved in heart development and microRNAs.

Network of target genes involved in cardiac development and microRNAs. Ten candidate genes involved in cardiac development were identified as potential targets for microRNAs selected from the differential expression profile of SV cardiac tissues. The identification of 24 microRNAs with expression changes during cardiac development, thus contributing to the regulation of their potential targets, suggests a collaborative network of microRNAs and mRNAs involved in this process (Fig. 9).

\section{Discussion}

Genome-wide miRNA expression profiling was performed by deep sequencing of ventricular myocardium obtained from three spontaneously aborted fetuses with SV and three control aborted fetuses. Significant differences between miRNA expression profiles were observed between SV and control cardiac tissues. Multiple independent lines of evidence corroborate this profiling data. In this study, miRNA expression analyses by SOLiD sequencing correlated closely with real-time qRT-PCR results and were found to be in accordance with previous reports. Decreased miR-19 has been identified in the failure-prone heart (11) and down-regulation of miR-19b and miR-92a have been shown to participate in maintaining P19 cell self-renewal and inhibiting cardiac differentiation (12). Furthermore, loss-of-function of the miR-17-92 cluster in mice resulted in smaller embryos and immediate postnatal death of all animals due to ventricular septal defects (13). In this study, the observation that miR-19b and miR-92a were associated with the occurrence and development of fetal SV malformations is in accordance with these studies (11-13).

This study identified 48 differentially expressed miRNAs in a comparison of SV and control cardiac tissues. These included miR-133a, miR-126, miR-206 and miR-27a, which have been previously confirmed to be involved in cardiac development. The absence of miR-133a expression results in ectopic expression of smooth muscle genes in the heart and aberrant cardiomyocyte proliferation (8). Targeted deletion of miR-126 displays defective cardiac neovascularization in mice that survive myocardial infarction (14); miR-206 is involved in apoptotic cell death in myocardial infarction by post-transcriptional repression of IGF-1 (15); and miR-27a regulation of $\beta$-MHC gene expression by targeting TR $\beta 1$ has been identified in cardiomyocytes (16). Other differentially expressed miRNAs between SV and control cardiac tissues were not investigated and further research is required to evaluate their roles in cardiac development.

Functional roles for differentially expressed miRNAs identified in this study were categorized according to cellular process, regulation of biological process and metabolic process, thus indicating intense biological change in fetuses with SV. Pathway-Express analysis identified the WNT and mTOR signaling pathways as the most significant pathways putatively affected by the differential expression of miRNAs. Activation of WNT signaling is critical for the induction of myocardial hypertrophy and cardiomyopathy (17). Furthermore, previous studies have shown that congenital cardiac anomalies induced by the dysfunction of myocardial cell proliferation and apoptosis are caused by dysfunction of the WNT signaling pathway (18) possibly mediated by miRNA targeting of signaling inhibitors (19). The myocardial mTOR signaling pathway is associated with physiological and pathological hypertrophies (20). These data provide further evidence of the mechanism of cardiac development.

Ten candidate genes (NOTCH1, WNT1, PTEN, AKT2, PDK1, TBX5, FOXP1, HAND1, GATA4 and GATA6) have been identified with an important role in cardiac development. Mice deficient in PDK1 in cardiac muscle had thinner ventricular walls, enlarged atria and right ventricles (21) and knockdown of the TBX5 gene caused cardiac failure as a result of down-regulation of cardiac myogenesis genes (22). Furthermore, absence of HAND1 in mice results in embryonal lethality, as well as a wide spectrum of cardiac abnormalities including failed cardiac looping, defective chamber septation and impaired ventricular development (23). The compound heterozygosity of GATA4 and GATA6 results in embryonic lethality by E13.5 accompanied by cardiovascular defects, including thin-walled myocardium, ventricular and aortopulmonary septal defects, and abnormal smooth muscle 
development (24). These genes were identified as potential targets for miRNAs which were aberrant in SV cardiac tissues. The identification of 24 miRNAs with expression changes during development of the heart, thus contributing to the regulation of their potential targets, suggests a collaborative network of miRNAs and mRNAs involved in this process. The majority of miRNAs target more than one gene and conversely a given mRNA could be the target of several miRNAs. For example, HAND1, a basic helix-loop-helix (bHLH) transcription factor essential for mammalian heart development was identified as a potential target of five miRNAs: miR-92a, miR-let-7d, miR-let-7e, miR-266-3p and miR-335. Decreased expression of these five miRNAs leads to up-regulation of HAND1. Furthermore, miR-575 and miR-429 target genes such as GATA-4, are involved in cardiac development. It is apparent that miRNAs target genes/transcription factors that have a role in cardiac development although the collaborative network of microRNAs and mRNAs requires further investigation.

The 48 miRNAs differentially expressed in SV identified in this study provide valuable evidence for elucidation of the pathogenesis of SV. A number of these miRNAs have known cardiac development correlations, while the functions of others identified in this study remain to be investigated. Gene ontology and Pathway-Express analysis of these differentially expressed miRNAs indicated involvement in the WNT and mTOR signaling pathways. The candidate genes involved in cardiac development were identified as potential targets for these differentially expressed microRNAs and the collaborative network of microRNAs and cardiac development-related mRNAs was constructed from this information. These data provide further understanding of the mechanism underlying the occurrence and development of fetal SV malformations.

\section{Acknowledgements}

The study was supported by grants from the National Natural Science Foundation of China (no. 81070500) and the Open Research Fund of the State Key Laboratory of Bioelectronics Southeast University (no. 2009C15).

\section{References}

1. Yang XY, Li XF, Lu XD and Liu YL: Incidence of congenital heart disease in Beijing, China. Chin Med J (Engl) 122: 1128-1132, 2009.

2. Fixler DE, Nembhard WN, Salemi JL, Ethen MK and Canfield MA: Mortality in first 5 years in infants with functional single ventricle born in Texas, 1996 to 2003. Circulation 121: 644-650, 2010.

3. Atz AM, Travison TG, Williams IA, Pearson GD, Laussen PC, Mahle WT, Cook AL, Kirsh JA, Sklansky M, Khaikin S, Goldberg C, Frommelt M, Krawczeski C, Puchalski MD, Jacobs JP, Baffa JM, Rychik J and Ohye RG: Prenatal diagnosis and risk factors for preoperative death in neonates with single right ventricle and systemic outflow obstruction: screening data from the Pediatric Heart Network Single Ventricle Reconstruction Trial*. J Thorac Cardiovasc Surg 140: 1245-1250, 2010.

4. Mohun TJ, Leong LM, Weninger WJ and Sparrow DB: The morphology of heart development in Xenopus laevis. Dev Biol 218: 74-88, 2000.

5. Huang ZP, Neppl RL and Wang DZ: MicroRNAs in cardiac remodeling and disease. J Cardiovasc Transl Res 3: 212-218, 2010

6. Wang DZ: MicroRNAs in cardiac development and remodeling. Pediatr Cardiol 31: 357-362, 2010.
7. Zhao Y, Ransom JF,Li A, Vedantham V, von Drehle M, Muth AN, Tsuchihashi T, McManus MT, Schwartz RJ and Srivastava D: Dysregulation of cardiogenesis, cardiac conduction, and cell cycle in mice lacking miRNA-1-2. Cell 129: 303-317, 2007.

8. Liu N, Bezprozvannaya S, Williams AH, Qi X, Richardson JA, Bassel-Duby R and Olson EN: microRNA-133a regulates cardiomyocyte proliferation and suppresses smooth muscle gene expression in the heart. Genes Dev 22: 3242-3254, 2008.

9. Morton SU, Scherz PJ, Cordes KR, Ivey KN, Stainier DY and Srivastava D: microRNA-138 modulates cardiac patterning during embryonic development. Proc Natl Acad Sci USA 105: 17830-17835, 2008.

10. Catalucci D, Latronico MV and Condorelli G: MicroRNAs control gene expression: importance for cardiac development and pathophysiology. Ann NY Acad Sci 1123: 20-29, 2008.

11. van Almen GC, Verhesen W, van Leeuwen RE, van de Vrie M, Eurlings C, Schellings MW, Swinnen M, Cleutjens JP, van Zandvoort MA, Heymans S and Schroen B: MicroRNA-18 and microRNA-19 regulate CTGF and TSP-1 expression in age-related heart failure. Aging Cell: April 18, 2011 (Epub ahead of print).

12. Hu DL, Liu YQ, Chen FK, Sheng YH, Yang R, Kong XQ, Cao KJ, Zhang JS and Qian LM: Differential expression of microRNAs in cardiac myocytes compared to undifferentiated P19 cells. Int J Mol Med 28: 59-64, 2011

13. Ventura A, Young AG, Winslow MM, Lintault L, Meissner A, Erkeland SJ, Newman J, Bronson RT, Crowley D, Stone JR, Jaenisch R, Sharp PA and Jacks T: Targeted deletion reveals essential and overlapping functions of the miR-17 through 92 family of miRNA clusters. Cell 132: 875-886, 2008.

14. Wang S, Aurora AB, Johnson BA, Qi X, McAnally J, Hill JA, Richardson JA, Bassel-Duby R and Olson EN: The endothelialspecific microRNA miR-126 governs vascular integrity and angiogenesis. Dev Cell 15: 261-271, 2008.

15. Shan ZX, Lin QX, Fu YH, Deng CY, Zhou ZL, Zhu JN, Liu XY, Zhang YY, Li Y, Lin SG and Yu XY: Up-regulated expression of miR-1/miR-206 in a rat model of myocardial infarction. Biochem Biophys Res Commun 381: 597-601, 2009.

16. Nishi H, Ono K, Horie T, Nagao K, Kinoshita M, Kuwabara Y, Watanabe S, Takaya T, Tamaki Y, Takanabe-Mori R, Wada H, Hasegawa K, Iwanaga Y, Kawamura T, Kita T and Kimura T: MicroRNA-27a regulates beta cardiac myosin heavy chain gene expression by targeting thyroid hormone receptor beta1 in neonatal rat ventricular myocytes. Mol Cell Biol 31: 744-755, 2011.

17. Malekar P, Hagenmueller M, Anyanwu A, Buss S, Streit MR, Weiss CS, Wolf D, Riffel J, Bauer A, Katus HA and Hardt SE: Wnt signaling is critical for maladaptive cardiac hypertrophy and accelerates myocardial remodeling. Hypertension 55: 939-945, 2010.

18. Han SP, Pan Y, Peng YZ, Gu XQ, Chen RH and Guo XR: Folbp1 promotes embryonic myocardial cell proliferation and apoptosis through the WNT signal transduction pathway. Int J Mol Med 23: 321-330, 2009.

19. Liu Y, Huang T, Zhao X and Cheng L: MicroRNAs modulate the Wnt signaling pathway through targeting its inhibitors. Biochem Biophys Res Commun 408: 259-264, 2011.

20. Kemi OJ, Ceci M, Wisloff U, Grimaldi S, Gallo P, Smith GL, Condorelli $\mathrm{G}$ and Ellingsen $\mathrm{O}$ : Activation or inactivation of cardiac $\mathrm{Akt} / \mathrm{mTOR}$ signaling diverges physiological from pathological hypertrophy. J Cell Physiol 214: 316-321, 2008.

21. Mora A, Davies AM, Bertrand L, Sharif I, Budas GR, Jovanovic S Mouton V, Kahn CR, Lucocq JM, Gray GA, Jovanovic A and Alessi DR: Deficiency of PDK1 in cardiac muscle results in heart failure and increased sensitivity to hypoxia. EMBO J 22: 4666-4676, 2003.

22. Lu JH, Lu JK, Choo SL, Li YC, Yeh HW, Shiue JF and Yeh VC: Cascade effect of cardiac myogenesis gene expression during cardiac looping in tbx 5 knockdown zebrafish embryos. J Biomed Sci 15: 779-787, 2008

23. Reamon-Buettner SM, Ciribilli Y, Traverso I, Kuhls B, Inga A and Borlak J: A functional genetic study identifies HAND1 mutations in septation defects of the human heart. Hum Mol Genet 18: 3567-3578, 2009.

24. Xin M, Davis CA, Molkentin JD, Lien CL, Duncan SA, Richardson JA and Olson EN: A threshold of GATA4 and GATA6 expression is required for cardiovascular development. Proc Natl Acad Sci USA 103: 11189-11194, 2006. 